27. Takebayashi, S Grobe, H. von Bassewitz. D. B., and Therman, H.: Ult rastractural aspects of vessel alterations in homocystinuria. Virchow's Arch. Abt. A Pathol. Anat.. 354: 4 (1971).

28. Tandler, B. T., Erlandson. R. A., and Wynder, E. L..: Riboflavin and mouse hepatic cell structure and function. Amer. J. Pathol.. 52: 69 (1968)

29. Tanikawa, L.: Ultrastructural Aspects of the I.jver and Its Disorders (lgaker Shoin, I.td., Tokyo, 1968).

30. Uhlendorf, B. W.. Conerly, E. R., and Mudd. S. H.: Homocystinuria: Siudies in tissue culture. Pediat. Res., 7: 645 (197.3)

31. Wong, P. W. K., and Fresco, R.: Tissue cystathionine in mice treated with cysteine and homoserine. Pediat. Res.. 6: 172 (1972).

32. Wong, P. W. K Justice. P. Weiss. E. Hruby, M. and Diamond, E.: A family with four cases of 5.10 -methylenetetrahydrofolate reductase deficiency. (In preparation $)$

33. Wong. P. W. K.. Schwarz. V.. and Komrower. (3. M.: The biosynthesis of cystathionine in patients with homocystinuria. Pediat. Res.. 2: 149 (1968)

34. The atuthors would like to thank K. Curley, N. Becker, and K. Jarosius for their technical assistance and Drs. B. Chomet, Orville T. Batey and Mary B. Buschman for their suggestions in the interpretations of brain and liver elect ron micrographs.

35. This study was supported by Public Health Service Research Grant no. Rol N508532NTN and a grant from the Illinois Department of Mental Health

36. Requests for reprints should be addressed to: Paul W K Wong M.D. Department of Pediatrics. Presbyterian-St. Luke's Medical Center, Rush Medical School. Chicago, IIl. 60612 (USA)

37. Accepted for publication December 18, 1975.

\title{
Effects of Calcium on Intestinal Mucin: Implications for Cystic Fibrosis
}

\author{
J. F. FORSTNER ${ }^{24}$ AND G. G. FORSTNER \\ Research Institute, The Hospital for Sick Children, Toronto, Ontario, Canada
}

\section{Extract}

A major feature of the disease cystic fibrosis is the excessive concentration of mucus within ducts and glands of mucousproducing organs. Some mucous secretions also show an eleration in calcium concentration. U'sing purified rat intestinal goblet cell mucin as a model mucin, we have investigated the effect of millimolar additions $(1-25 \mathrm{mM})$ of $\mathrm{CaCl}_{2}$ on the physical properties of the mucin. Isotonicity of incubation media was preserved in order to mimic in vivo conditions. $\mathrm{CaCl}_{2}(8-15 \mathrm{mM})$ caused a $15-33 \%$ decrease in viscosity, no change in electrophoretic mobility in acrylamide gels, and a $20-30 \%$ decrease in solubility of the mucin. Solubility changes were reversed by the addition of EDTA $(20 \mathrm{mM})$ to incubations. Insolubility was also produced in incubations of mucin with a mixture of soluble intestinal contents ( $\mathrm{NaCl}$ washings ). These findings strongly suggest that the mucin became smaller and more dense as calcium was added, a process most probably achieved by loss of intramolecular water.

\section{Speculation}

It is hypothesized that elevated concentrations of calcium within glycoprotein secretions of patient with cystic fibrosis may substantially increase the density and insolubility of mucins, promoting the formation of mucous "plugs."

Mucous secretions of patients with cystic fibrosis are excessive in amount in salivary glands, bronchi, intestine, gall bladder, and cervix $(7,12,14)$. The calcium concentration in many of these secretions is also high, ranging from "slightly elevated" to over 100 -fold in excess of normal (12). It has been hypothesized that $\mathrm{Ca}$ may contribute to the formation of mucous "plugs" in glands and ducts by causing polymerization, aggregation, or gel formation of otherwise normal mucin macromolecules. A few studies have shown that $\mathrm{Ca}$ is responsible for aggregation of small salivary proteins $(4,5,13)$, but no studies have been performed to discover whether $\mathrm{C}$ a changes the physical properties of purified mucin macromolecules of intestinal or bronchial origin.

Over the past few years a native goblet cell mucin has been purified in our laboratory from rat small intestine $(9,11)$. It resembles mucins purified by others from several human and animal organs $(1,4,6,17-19)$, in that it is a polydisperse viscous glycoprotein rich in carbohydrate, containing high quantities of serine, threonine, and proline within the peptide core

We have used rat goblet cell mucin as a model for the investigation of $\mathrm{Ca}$-mucin interaction. Previously we showed that rat mucin binds $C$ a ions, especially under conditions of low ionic strength, but that during binding Ca caused only minor physical changes in the mucin $(8)$. In the present study we have measured the effects of $\mathrm{C}$ a upon some of the physical properties of mucin in isotonic media in order to mimic more closely in vivo conditions. Our results indicate that $\mathrm{Ca}$ may alter the three-dimensional architecture of mucin so as to increase its density and exclude water. It is postulated that this mechanism may be involved in the formation of mucous plugs in cystic fibrosis.

\section{METHODS}

The preparation of goblet cell mucin (GCM) from rat intestine, radioactive labeling of the mucin using precursor $\left[{ }^{14} \mathrm{C}_{1}\right]$ glucosamine, the techniques of polyacrylamide disc gel electrophoresis, analytic ultracentrifugation, and measurement of solubility of the mucin have been described in detail in earlier publications $(8,9$, 11). Minor modifications and specific details are included as appropriate under Results.

Intestinal washings, when required for solubility experiments, were collected by washing the entire small intestine of each of 10 rats with approximately $20 \mathrm{ml} 0.15 \mathrm{M} \mathrm{NaCl}$. The washings were pooled, centrifuged at $4^{\circ}$ at $30,000 \times g$ for $15 \mathrm{~min}$ to remove particulate material, and the suernatant solutions saved. The soluble supernatant fluid was stored frozen in a dilute state or else concentrated isotonically 10 -fold by an Amicon Dia-Flo ultrafilter 
and then stored frozen as a concentrate. Both dilute and concentrated washing solutions were thawed immediately before use in solubility experiments with goblet cell mucin.

The water used in the preparation of all solutions was rendered ion free as described earlier (8). Chloride salts of various cations ( $\mathrm{Ba}, \mathrm{Zn}, \mathrm{Mn}, \mathrm{Mg}$ ) were made using anhydrous powders (oven dried to constant weight) of the chloride salts. The usual buffers in solubility studies included $0.01 \mathrm{M}$ Tris- $\mathrm{HCl}$ in $0.14 \mathrm{M} \mathrm{NaCl}, \mathrm{pH}$ 7.4 , or $0.155 \mathrm{M}$ Tris- $\mathrm{HCl}$, pH 7.4. In a few instances the buffer used was $0.15 \mathrm{M}$ Hepes, $\mathrm{pH} 7.4$, and the results were identical with those obtained using Tris or Tris- $\mathrm{NaCl}$ buffers.

Viscosity of goblet cell mucin was measured in a CannonUbbelohde semimicro capillary viscometer at $20^{\circ}$ as described earlier (8) and in a Brookfield Synchrolectric model LVT rotary viscometer over a wide range of shear rates (22-230 sec '). Units of viscosity were centistokes and centipoises for capillary and rotary viscometry, respectively, and were converted into units of viscosity "number" by the following equation: $\eta \mathrm{sp} / \mathrm{c}=\frac{\eta-\eta_{0}}{\eta_{0}} \div \mathrm{c}$, where $\eta_{0}$ is the viscosity of the solvent, $\eta$ is the mucin viscosity in that solvent, and $\mathrm{c}$ is the concentration of goblet cell mucin in grams, dry weight per $100 \mathrm{ml}$. Viscosity of the mucin at zero shear was obtained from viscosity data over a range of shear rates extrapolated to zero.

\section{RESULTS}

\section{EFFECT OF Ca ON VISCOSITY OF GOBLET CELLL MUCIN}

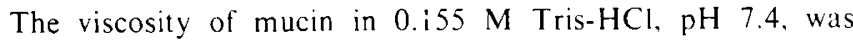
examined over a range of mucin concentration and shear rate values using both capillary and rotary viscometry (Fig. 1). In the absence of $\mathrm{Ca}$ the viscosity varied with both shear rate and mucin concentration. In general, the viscosity was higher at low shear rates $\left({ }_{-}-\right.$) and underwent a sharp increase at concentrations of mucin above $0.5 \mathrm{~g} / 100 \mathrm{ml}$, at which visible gelation began. At the higher shear rates of capillary viscometry $(--)$ gelation was not visible. In both cases the addition of $\mathrm{CaCl}_{2}(5-25 \mathrm{mM})$ caused a decrease in viscosity, which was approximately $15-18 \%$ for zero shear and $33 \%$ for high shear conditions in $10 \mathrm{~m} \mathrm{M} \mathrm{CaCl}_{2}$ (Fig. 1). At the higher concentrations of mucin, Ca appeared to retard gel formation at zero shear.

Under no conditions of goblet cell mucin concentration. temperature variation $\left(20^{\circ}-37^{\circ}\right)$, shear rate, or $\mathrm{CaCl}_{2}$ concentration

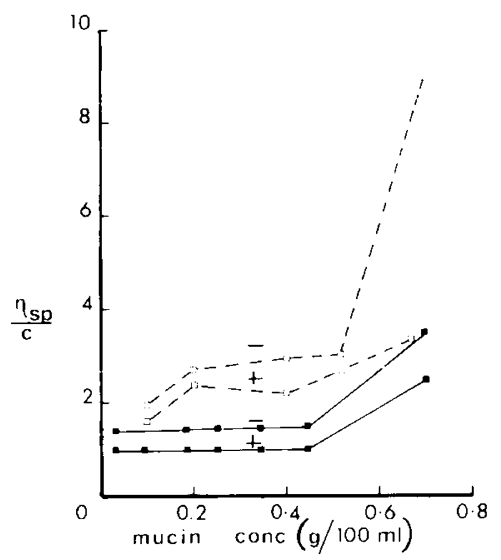

Fig. 1. Viscosity of goblet cell mucin. Rotary viscometry was performed over a range of shear rates $(22.230 \mathrm{sec}$ ') extrapolated to give zero shear

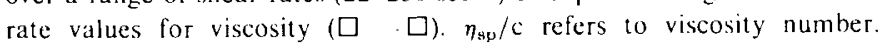
Capillary viscometry values (-D) were obtained using a CannonUbbelohde semimicroviscometer. + and - refer to the presence or absence, respectively, of $10 \mathrm{mM} \mathrm{CaCl}_{2}$ in the buffer solvent which was either $0.155 \mathrm{M}$-Tris-HCl, pH 7.4, or $0.01 \mathrm{M}$ Tris-HCl-0.14 M NaCl, pH 7.4. Each viscosity value was the average of triplicate determinations which did not exceed a range of more than \pm 0.05 viscosity number units.

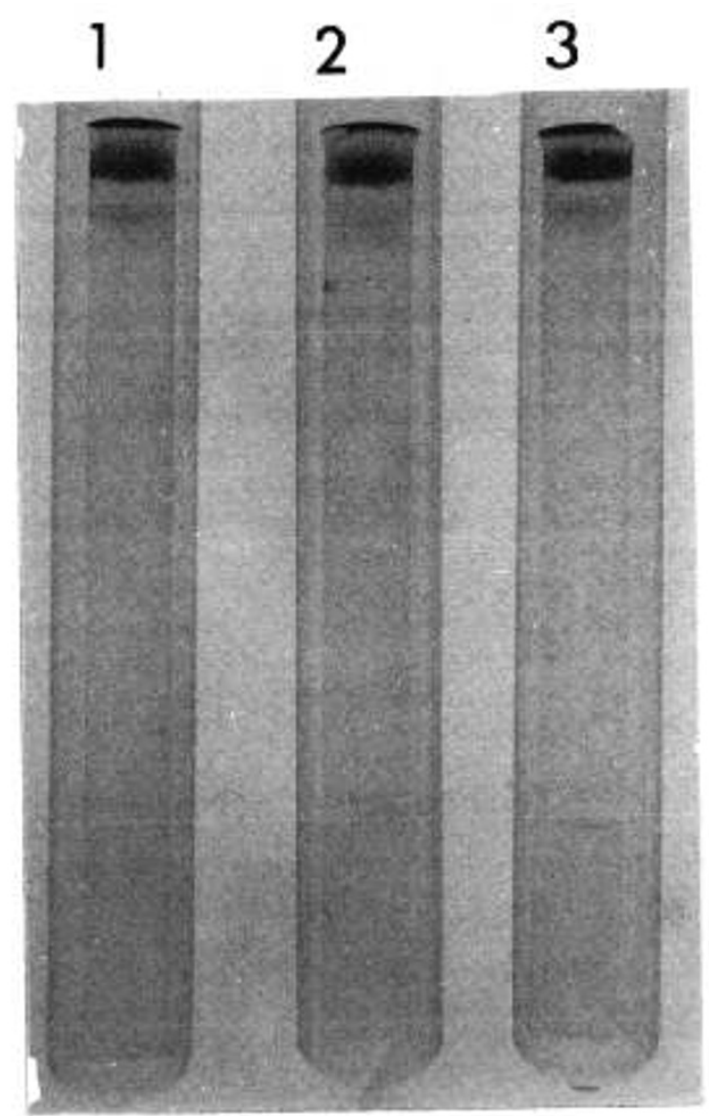

Fig. 2. Polyacrylamide disc gel electrophoresis of mucin. Goblet cell mucin $(32 \mu \mathrm{g} \mathrm{dry} \mathrm{wt})$ was mixed with bromphenol blue dye in $60 \%$ sucrose with or without $\mathrm{CaCl}_{2}(8 \mathrm{mM})$ in a final volume of $0.05 \mathrm{ml}$. Samples were applied to $4 \%$ acrylamide gels made in $0.15 \mathrm{M}$ Tris-borate buffer, pH 8.6. with or without the addition of $8 \mathrm{mM} \mathrm{CaCl}_{2}$. Gels were run for $55 \mathrm{~min}$ at 2 $\mathrm{mA} / \mathrm{tube}$ and subsequently stained with periodic acid-Schiff reagent. In gel $I$ there was no $\mathrm{Ca}$ in the mucin sample or the gel: in gel 2 there was $\mathrm{CaCl}_{2}$ in the gel and the buffer during electrophoresis, and in gel 3 there was $\mathrm{CaCl}_{2}$ in the mucin sample, the gel, and the buffer during electrophoresis.

(1 $-50 \mathrm{mM})$ did Ca cause an elevation in viscosity suggestive of gelation or polymerization of the macromolecule.

\section{POLYACRYLAMIDE DISC GEI ELECTROPHORESIS}

In an attempt to rule out dissociation by $\mathrm{Ca}$, which might have accounted for the lowering of viscosity, goblet cell mucin was subjected to electrophoresis in $4 \%$ polyacrylamide gels at $\mathrm{pH} 8.6$ in the presence and absence of $\mathrm{CaCl}_{2}$ in the gel and buffer systems (Fig. 2). As described earlier (9), the basic pattern consisted of one broad periodic acid-Schiff-positive band near the origin and two faint bands below. In the presence of $\mathrm{CaCl}_{2}(3,8$, and $25 \mathrm{mM})$, the mucin did not undergo any detectable change in band widths, intensity of stain, or mobility.

\section{SEDIMENTATION VEIOCITY STUDIFS}

Goblet cell mucin $(2.5 \mathrm{mg} \mathrm{dry} \mathrm{wt} / \mathrm{ml})$ was subjected to boundary ultracentrifugation in $0.01 \mathrm{M}$ Tris- $\mathrm{HCl}-0.14 \mathrm{M} \mathrm{NaCl}$ buffer, $\mathrm{pH}$ 7.4 , containing $0,1,5$, and $10 \mathrm{mM} \mathrm{CaCl}_{2}$. In the absence of $\mathrm{Ca}$, the Schlieren optical pattern consisted of a single peak with a leading shoulder (previously published (10)). No change in pattern was observed in the presence of $\mathrm{CaCl}_{2}$. Thus, there was no indication, by either gel electrophoresis or sedimentation pattern, that $\mathrm{Ca}$ had caused the mucin to dissociate into lighter or smaller fragments.

It was observed, however, that the addition of $\mathrm{CaCl}_{2}$ to $\mathrm{GCM}$ samples caused a decrease $(18 \%$ at $10 \mathrm{mM} \mathrm{CaCl})$ in the measurable concentration of GCM, as determined from Schlieren 
peak areas (Table 1, column 3). This happened despite the original addition of exactly $2.5 \mathrm{mg}$ mucin/ml to each cell, and was associated with a small but significant increase in calculated $s_{20 . u}$ values (column 4). It was suspected that some of the mucin may have agg regated with $\mathrm{CaCl}_{2}$ and sedimented rapidly to the bottom of the ultracentrifuge cell before the attainment of maximum rotor speed. Thus only the remaining soluble mucin was detected in Schlieren tracings. By comparing test samples with control GCM samples (no added $\mathrm{CaCl}_{2}$ ) having the same $\mathrm{GCM}$ concentration, $s_{20, u}$ values were seen to be identical ( $\mathrm{T}$ able 2 ). Thus the remaining soluble GCM in Ca-containing cells possessed sedimentation properties characteristic of the intact control mucin. Since $C a$ appeared to have primarily affected GCM solubility, separate experiments were conducted to examine solubility more directly.

\section{SOI.UBILITY}

A soluble mixture of mucin $(8.33 \mathrm{mg} \mathrm{dry} \mathrm{wt} / \mathrm{ml})$ in $0.01 \mathrm{M}$ Tris- $\mathrm{HCl}-0.14 \mathrm{M} \mathrm{NaCl}, \mathrm{pH} \mathrm{7.4,} \mathrm{became} \mathrm{visibly} \mathrm{insoluble} \mathrm{at} 4.25$. and $37^{\circ}$ after the addition of $\mathrm{CaCl}_{2}$ (final concentration $10 \mathrm{mM}$ ). Because of the scarcity of mucin, however. and the subjectivity of visual inspection for solubility, a quantitative microcentrifugation technique (8) was employed. Briefly, this method involved the incubation of ${ }^{14} \mathrm{C}$-radioactively labeled mucin $(0.25 \mathrm{mg})$ in isotonic buffer to which $\mathrm{CaCl}_{2}$ was added, followed by centrifugation of aliquots $(0.06 \mathrm{ml})$ in microhematocrit capillary tubes. Solubility was calculated as a percentage of control ( $\mathrm{C}$ a-free) samples by measuring the radioactivity of supernatant and pellet fractions.

Table 1. Sedimentation velocity of goblet cell mucin $(G C M)^{1}$

\begin{tabular}{|c|c|c|c|c|}
\hline & $\mathrm{CaCl}_{2}, \mathrm{mM}$ & $\begin{array}{l}\mathrm{GCM} \\
\text { added, } \\
\mathrm{mg} / \mathrm{m} !\end{array}$ & $\begin{array}{c}\text { GCM measured, } \\
\mathrm{mg} / \mathrm{ml} \%\end{array}$ & ${ }^{s} 20, w$ \\
\hline Control & 0 & 2.5 & 2.5 & 11.95 \\
\hline Test & 1 & 2.5 & $2.5(0)$ & 11.96 \\
\hline Control & 0 & 2.18 & 2.18 & 12.20 \\
\hline Test & 5 & 2.5 & $2.18(13)$ & 12.17 \\
\hline Control & 0 & 2.05 & 2.05 & 12.54 \\
\hline Test & 10 & 2.5 & $2.05(18)$ & 12.52 \\
\hline
\end{tabular}

${ }^{1} \mathrm{CaCl}_{2}$ and $\mathrm{GCM}$ were mixed to give the final concentrations shown in columns $l$ and 2. Sedimentation runs were performed at $20^{\circ}$ in a Beckman model $E$ analytic ultracentrifuge using double-sector cells at $48,000 \mathrm{rpm}$. The solvent was $0.01 \mathrm{M}$ Tris-HCl-0.14 M NaCl, pH 7.4 GCM concentrations in column 3 were determined from total peak areals of Schlieren tracings. $s_{20, u}$ values had standard deviations not greater than \pm 0.06 . Parentheses indicate the reduction in measured concentration of $\mathrm{GCM}$ as a percentage of control $\left(\right.$ no $\left.\mathrm{CaCl}_{2}\right)$ samples containing $2.5 \mathrm{mg} \mathrm{GCM} / \mathrm{ml}$.

Table 2. Relative effectiveness of several cations on mucin solubilit!:

\begin{tabular}{cc}
\hline $\begin{array}{c}\text { Chloride salt } \\
\text { of cation }(25 \mathrm{mM})\end{array}$ & $\begin{array}{c}\text { Effectiveness } \\
\pm \text { range }\end{array}$ \\
\hline $\mathrm{Zn}$ & $1.24 \pm 0.01$ \\
$\mathrm{Mn}$ & $1.13 \pm 0.05$ \\
$\mathrm{Mg}$ & $1.06 \pm 0.02$ \\
$\mathrm{Ca}$ & $1.00 \pm 0.00$ \\
$\mathrm{Ba}$ & $0.94 \pm 0.02$
\end{tabular}

${ }^{1}$ Incubations of ${ }^{14} \mathrm{C}$-labeled mucin in $0.01 \mathrm{M}$ Tris- $\mathrm{HCl}-0.14 \mathrm{M} \mathrm{NaCl}$ $\mathrm{pH} 7.4$, were carried out as described in text. The effect of $\mathrm{Ca}(25 \mathrm{mM})$ was to cause a decrease in solubility of $30 \%$. This value was arbitrarily set at 1.00 and other divalent cations were compared. Each value represents the average of four incubations \pm the total range obtained.

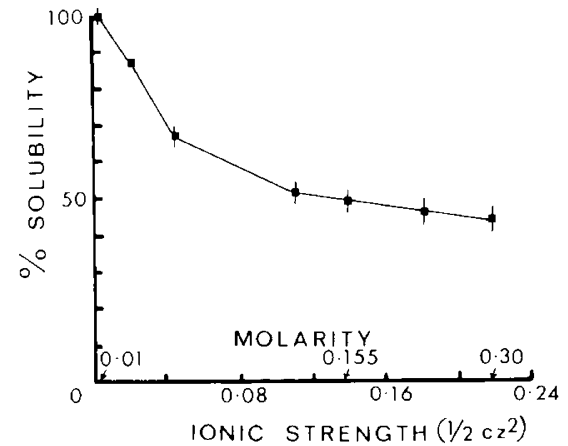

Fig. 3. Solubility of goblet cell mucin. Radioactively labeled $\left({ }^{14} \mathrm{C}\right)$ mucin was incubated in Tris-HCl buffers of increasing molarity for $30 \mathrm{~min}$ at room temperature. Each incubation contained $0.67 \mathrm{mg}$ dry wt of mucin. about $500-1.000 \mathrm{cmm}$, and was $0.2 \mathrm{ml}$ in volume. After centrifugation at $12.500 \times g$ for $5 \mathrm{~min}$, radioactivity in the pellet and supernatant solutions was determined and solubility was calculated as a percentage. Ionic strength was determined from the formula $0.5 \mathrm{cz}^{2}$. Each value represents the mean of values obtained from three separate incubations. Each vertical bar represents the total range of values obtained. Radioactivity determination was performed on duplicate samples by scintillation counting in Brayss solution. Total recovery of mucin radioactivity in pellet plus supernatant was $100 \% \pm 2 \%$.

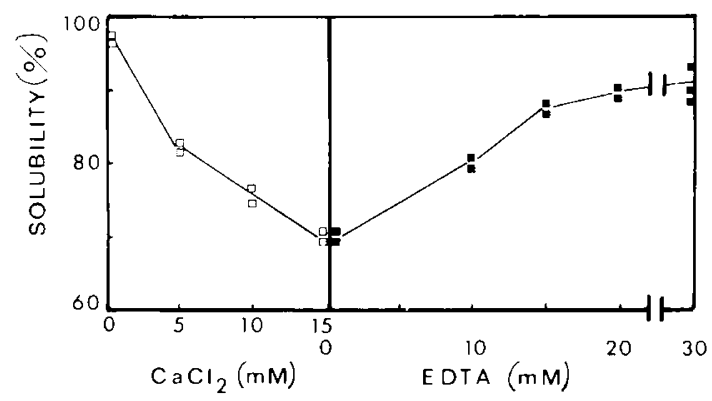

Fig. 4. Solubility of mucin with $\mathrm{Ca}$ and EDTA. ${ }^{14} \mathrm{C}$-Labeled goblet cell mucin $(0.25 \mathrm{mg})$ was incubated in $0.01 \mathrm{M}$ Tris- $\mathrm{HCl}-0.14 \mathrm{M} \mathrm{NaCl}, \mathrm{pH} 7.4$, containing increasing amounts of $\mathrm{CaCl}_{2}$ and solubility determined as described in the legend to Figure 4 . The effect of $\mathrm{Ca}$ is shown on the left. Separate incubations all containing $15 \mathrm{mM} \mathrm{CaCl}$. plus varying amounts of $\mathrm{Na}_{2}$ EDTA were performed, and solubility values are shown on the right. Each value is the average of two incubations.

Effect of Ionic Strength on Solubility. Figure 3 shows that the solubility of mucin in Tris- $\mathrm{HCl}$ buffer, $\mathrm{pH} 7.4$, decreased progressively with increasing molarity of buffer until, at $0.155 \mathrm{M}$, solubility reached $50 \%$ of control values. Between 0.155 and $0.3 \mathrm{M}$ Tris, however, only a small (3.5\%) drop in solubility occurred. In $0.01 \mathrm{M}$ Tris- $\mathrm{HCl}-0.14 \mathrm{M} \mathrm{NaCl}, \mathrm{pH} 7.4$, solubility was $7080 \%$ of the control (not shown). In subsequent experiments to test the spccific effects of $\mathrm{CaCl}_{2}$ on mucin solubility in various buffers. ionic strength was equalized in samples by adding extra buffer ions to control ( $\mathrm{C}$ a-free) incubations in order to compensate for the addition of $\mathrm{CaCl}_{2}(1-25 \mathrm{mM})$ to test samples.

Effect of $\mathrm{Ca}$ on Mucin in Isotonic Buffer. $\mathrm{CaCl}_{2}$ was added in increasing concentrations to incubations of goblet cell mucin in either $0.155 \mathrm{M}$ Tris- $\mathrm{HCl}$ or $0.01 \mathrm{M}$ Tris-HCl-0.14 M NaCl, $\mathrm{pH}$ 7.4. Figure 4 (left) shows that $C$ a caused a progressive decrease in solubility down to about $70 \%$ of the control (Ca-free) incubation. This was true for both buffers. It is of interest to note that the degree of insolubility produced by $10 \mathrm{mM} \mathrm{CaCl}{ }_{2}$ was approximately $22 \%$, which is very close to the previously measured decrease (18\%) (Table 1) in soluble GCM during analytic ultracentrifugation. The two findings support the interpretation that $\mathrm{Ca}$ caused a decrease in the solubility of mucin during sedimentation velocity runs. 
In subsequent experiments the mucin was incubated in isotonic buffer containing $15 \mathrm{mM} \mathrm{CaCl}_{2}$ to which increasing $\mathrm{Na}_{2}$ EDTA was added (Fig. 4, right). With increasing EDTA, the solubility of mucin was gradually restored to about $90 \%$ of control levels.

Effect of Ca on Mucin in Intestinal Luminal Washings. In order to find out whether intestinal mucin would respond to $\mathrm{Ca}$ in the same fashion within a more physiologic environment, the following experiment was performed. ${ }^{14} \mathrm{C}$-Labeled goblet cell mucin was incubated with or without $\mathrm{CaCl}_{2}$ for $30 \mathrm{~min}$ at $37^{\circ}$ in either dilute or 10-fold concentrated intestinal washings. Figure 5 indicates that in each case $\mathrm{Ca}$ caused a progressive drop in solubility to approximately $50 \%$ of control values. Thus goblet cell mucin became partly insoluble with $\mathrm{Ca}$ in a medium containing isotonic $\mathrm{NaCl}$ and normal soluble luminal contents, which are presumed to include bacterial products, digested food products, pancreatic and other enzymes, bile salts, cellular debris, and other proteins, lipids, glycoproteins, and ions.

Specificity of Ca Ions. It was of interest to determine whether the solubility of mucin was affected by other divalent or monovalent cations. As seen in Table 2, the Ca effect was arbitrarily designated as 1.00 for $25 \mathrm{mM} \mathrm{CaCl}_{2}$, and the effectiveness of other cations related to it. $\mathrm{Zn}, \mathrm{Mn}$, and $\mathrm{Mg}$ were all found to be slighly more effective, and $\mathrm{Ba}$ slightly less effective than $\mathrm{Ca}$. Tris- $\mathrm{HCl}$ and $\mathrm{NaCl}$ were much less effective. Thus monovalent cations had very little effect, but all of the divalent cations tested were effective and there did not seem to be a high degree of specificity for Ca.

\section{DISCUSSION}

Our results indicate that calcium, in concentrations known to obtain in some secretions in cystic fibrosis (13), crucially modifies the behavior of a model epithelial mucin under isotonic conditions, making it denser, less viscous, and more insoluble. The fact that viscosity fell but the molecule clearly became heavier, as indicated by its solubility characteristics, strongly suggests that the mucin became smaller and more dense as calcium was added, a process most probably achieved by loss of intramolecular water. Insolubility, which might be taken as the most dramatic and advanced evidence of this process, was not seen in hypotonic media (8). Clearly, therefore, the divalent cation effect required a near isotonic background, and these conditions are precisely those which are encountered in secretions in vivo (12). Insolubility was also not limited to simple test tube conditions, but could be demonstrated in the presence of complex organic contents of the

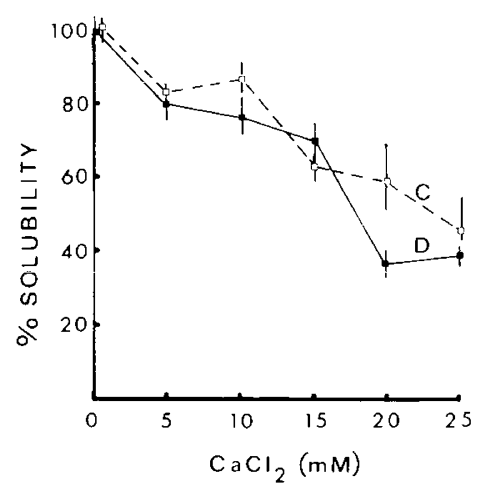

Fig. 5. Solubility of mucin in intestinal washings. Intestinal washings were obtained from 10 rats using $20 \mathrm{ml} 0.15 \mathrm{M} \mathrm{NaCl} / \mathrm{rat}$. The washings were centrifuged at $30,000 \times g$ for 30 min to remove particulate matter and the supernatant material either stored or concentrated isotonically 10 -fold, and then stored at $-20^{\circ}$. Incubation of mucin in the intestinal washing solutions was carried out as described in the legend of Figure 5 with increasing $\mathrm{CaCl}_{2}$ additions. Values represent the average (and total range of values) of three incubations. $C$ and $D$ refer to solubility in concentrated or dilute intestinal washings. intestinal lumen. It seems likely, therefore, that excessive calciun if present within cystic fibrosis mucous secretions, could substar. tially increase the density and reduce the solubility of mucins Whether other divalent cations play an important physiologic rol in altering mucins is open to conjecture. Only calcium is likely t. be present in sufficient concentration extracellularly to have $a r_{1}$ appreciable effect.

Decreased hydration and size, increased density, and loss of solubility indicate that the mucin sheet may become more granulat and less gelatinous in the presence of calcium. These changes mar explain the "hyperpermeability" described by Gibson et al. (12) for cystic fibrosis gastrointestinal mucosa in vivo, and for salivary mucous films in vitro. Increased granularity might interfere with the spreading quality of the mucin over the epithelial surface, possibly decreasing its uniformity and leaving denuded hyperpermeable areas of intestinal surface.

The significance of our findings lies in the fact that mucins normally account for the viscosity of bronchial and intestinat secretions, and are major components of obstructive plugs in cystic fibrosis (14). Previous authors $(5,14)$ have shown that small molecular weight glycoproteins in saliva are aggregated by additional calcium, and that the aggregation is reversed by EDTA. Warton and Blomfeld (22) have described hydroxyapatite crystals in saliva of cystic fibrosis. Although these components may contribute to the turbidity which is characteristic of cystic fibrosis saliva $(7,13)$, they bear little resemblance to highly glycosylated mucin macromolecules. Whether rat intestinal mucin is appropriate as a model for human intestinal or bronchial mucin has not been unequivocally demonstrated. Rat mucin does, however, possess most of the features characteristic (9) of intact epithelial mucins isolated from many organs, including a bronchial mucin from cystic fibrosis patients (19).

In addition to the implications for cystic fibrosis, the present study raises certain questions relevant to the normal function of mucins. It has been hypothesized, for example, that mucous provides protective "waterproofing" for epithelial surfaces (16, 20 ). Anatomically, the mucous blanket in the intestine occupies a zone through which all solutes destined for absorption must penetrate. Therefore, agents such as $C$ a ions which alter mucous structure might be expected to influence water or solute transport. This may be analogous to the effects of $C$ a upon ion fluxes through artificial phospholipid membranes (15) or collagen membranes (2), where Ca produces a "tightening" of structure and neutralization of membrane negative charge.

The interaction of $\mathrm{Ca}$ and intestinal mucin may also have physiologic significance within normal goblet cells of the intestine. Warner and Coleman (21) have shown recently by electron probe analysis that goblet cells contain a major share of the total intestinal Ca. The reason for this distribution is not clear, but in view of the present work, it is possible that $\mathrm{Ca}$ helps to keep mucin dense or compact within the secretory granules of the cell. Once released into the lumen, the mucin would then be diluted, the $\mathrm{Ca}$ removed, and the mucin would swell and spread over the mucosal surface.

\section{SUMMARY}

Millimolar additions $(8-25 \mathrm{mM})$ of $\mathrm{CaCl}_{2}$ to rat intestinal goblet cell mucin in isotonic buffer media caused a $15-33 \%$ decrease in viscosity, no change in electrophoretic mobility, and a $20-30 \%$ decrease in solubility of the mucin. If elevated Ca concentrations similarly affect the solubility of human mucins, they could contribute to mucous "plug" formation in cystic fibrosis.

\section{REFERENCES AND NOTES}

I. Allen, A., and Snary, D.: The structure and function of gastric mucous. Gut, 13 . 666 (1972).

2. Bartolini, A., Gliozzi, A., and Richardson, I. W.: Electrolytes control flows of water and sucrose through collagen membranes. J. Membrane Biol., 13: 283 (1973). 
3. Bella, A and Kim, Y S : Rat small intestinal mucin-Isolation and characterization of a water-soluble mucin fraction. Arch. Biochem. Biophys., 150:679 (1972).

4. Bettelheim, F. A.: Light-scattering studies of bovine submaxillary mucin Biochim. Biophys. Acta, 236: 702 (1971).

5. Boat, T. F., Wiesman, U. N., and Pallavicini, J. C.: Purification and properties of the calcium-precipitable protein in submaxillary saliva of normal and cystic fibrosis subjects. Pediat. Res., 8: 531 (1974).

6. Buddecke, E.: In: A. Gottschalk: Miscellaneous glycoproteins in glycoproteins, their composition, structure and function, p. 558 (Elsevier Publishing Co., Amsterdam, 1966).

7. di Sant'Agnese, P. A., and Talamo, R. C.: Pathogenesis and physiopathology of cystic fibrosis of the pancreas. N. Engl. J. Med., 277: 1287 (1967).

8. Forstner, J. F., and Forstner, G. G.: Calcium binding to intestinal goblet cell mucin. Biochim. Biophys. Acta, 386: 283 (1975).

9. Forstner, J. F., Jabbal, I, and Forstner, G. G.: Goblet cell mucin of rat small intestine: Chemical and physical characterization. Can. J. Biochem., 51: 1154 (1973).

10. Forstner, J. F., and Manery, J. F.: Calcium binding by human erythrocyte membranes. Biochem. J., 124: 563 (1971).

1I. Forstner, J. F., Taichman, N., Kalnins, V., and Forstner, G. G.: Intestinal goblet cell mucus isolation and identification by immunofluorescence of a goblet cell glycoprotein. J. Cell Sci., I2: 585 (1973)

12. Gibson, L. E., Matthews, W. J., Minihan, P. T., and Patti, J. A.: Relating mucous, calcium and sweat in a new concept of cystic fibrosis. Pediatrics, 48 . $695(1971)$.

13. Gugler, E. C., Pallavicini, J. C., Swerdlow, H., and di Sant'Agnese, P.: The role of calcium in submaxillary saliva of patients with cystic fibrosis. J. Pediat., $7 l$ :
585 (1967).

14. Jakowska, S.: Cystic Fibrosis and Related Human and Animal Diseases, p. 162 Gordon and Breach Scientific Publishing Co., New York).

15. Joos, R. W., and Carr, C. W.: The binding of calcium in mixtures of phospholipids. Proc. Soc. Exp. Biol. Med., 124: 1268 (1967)

16. Negus, V., Mucus. Proc. Roy. Soc. Med., 60: 75 (1967).

17. Pigman, W. and Herp, A.: Aspects biochimiques et physiologiques des glycoproteides des secretions muqueuses. Ann. Anat. Pathol., 17: 227 (1972)

18. Roberts, G. P.: Isolation and characterization of glycoproteins from sputum. Eur. J. Biochem., 50: 265 (1974).

19. Roussel, P., Lamblin, G., and Degand, P.: Heterogeneity of the carbohydrate chains of sulfated bronchial glycoproteins isolated from a patient suffering from cystic fibrosis. J. Biol. Chem., 250: 2114 (1975).

20. Taylor, M. The origins and functions of nasal mucus. Laryngoscope, 34: 612 (1974)

21. Warner, R. R., and Coleman, J. R.: Electron probe analysis of calcium transport by small intestine. J. Cell Biol., 64: 54 (1975)

22. Warton, K. L., and Blomfield, J.: Hydroxyapatite in the pathogenesis of cystic fibrosis. Brit. Med. J., 3: 570 (1971).

23. The authors are indebted to the Medical Research Council of Canada and the Canadian Cystic Fibrosis Foundation for financial support, to Dr. David Kells of the Department of Biochemistry, University of Toronto, for performing analytic ultracentrifugation studies, and to Mrs. Cecilia Feng for technical assistance.

24. Requests for reprints should be addressed to: J. F. Forstner, M.D., Research Institute, The Hospital for Sick Children, 555 University Ave. Toronto, Ontario M5G IX8 (Canada).

25. Accepted for publication December 18, 1975

Copyright (c) 1976 International Pediatric Research Foundation, Inc.

Printed in U.S.A.

Pediat. Res. 10: 613-620 (1976)

Erythrocytes sickle cell anemia hemoglobin $\quad \alpha$-thalassemia

\title{
Sickle Cell Syndromes. I. Hemoglobin SC- $\alpha$-Thalassemia
}

\author{
GEORGE R. HONIG, ${ }^{52}$ ' UNSAL GUNAY, R. GEORGE MASON, LOYDA N. VIDA, AND \\ CHRISTINE FERENC \\ University of Illinois Sickle Cell Center and Department of Pediatrics, The Abraham Lincoln School of Medicine,
}

University of Illinois Medical Center, Chicago, Illinois, USA

Extract

Hematologic and globin synthesis studies were performed in a black American family in which the genes for $\alpha$-thalassemia and hemoglobins $(\mathrm{Hb}) \mathrm{S}$ and $\mathrm{C}$ were segregating. The following distribution of these abnormalities was found: father, sickle cell trait $+\alpha$-thalassemia; mother, $\mathrm{HbC}$ trait $+\alpha$-thalassemia, propositus, HbSC $+\alpha$-thalassemia; older sibling, $\alpha$-thalassemia trait; and younger sibling, hemoglobin $\mathrm{H}$ disease.

The child with $\mathrm{HbSC}-\alpha$-thalassemia demonstrated more severe anemia and a more hemolytic picture than is typical of $\mathrm{HbSC}$ disease. Her erythrocytes exhibited decreased osmotic fragility in comparison with $\mathrm{HbSC}$ erythrocytes, but had an indistinguishable oxygen equilibrium curve and 2,3-diphosphoglycerate (2,3-DPG level. Erythrocyte sickling in the patient, however, was significantly reduced, with less than $35 \%$ sickle forms observed at nearly complete oxygen desaturation.

The sibling with hemoglobin $\mathrm{H}$ disease exhibited $26 \%$ Bart's $\left(\gamma_{4}\right)$ hemoglobin at birth, a level comparable with that seen in infants with $\mathrm{HbH}$ disease in Far Eastern populations. At age 5 months typical findings of mild hemoglobin $\mathrm{H}$ disease appeared, with $\mathrm{HbH}$ making up $6.5 \%$ of the total hemoglobin.

\section{Speculation}

The presence of $\alpha$-thalassemia in the proband of this study appeared to modify her $\mathrm{HbSC}$ disease so as to reduce its clinical severity as well as its pathologic potential. The ameliorative effect of $\alpha$-thalassemia would appear to be related to a reduction in the intracellular hemoglobin concentration in the patient's erythrocytes, but other factors may also be responsible for these changes. Further study of genetically modified sickle hemoglobinopathy syndromes may ultimately aid in the development of effective means for the treatment of these disorders.

The clinical expression of sickling disorders may vary widely, even among individuals having an apparently identical form of sickle cell disease. This variability has stimulated investigation of the role of genetic as well as nongenetic factors in the hematologic 